\title{
Effect of Inhibition of Nitric Oxide Synthesis on the Cardiovascular and Endocrine Responses to Hemorrhage in Conscious Rabbits
}

\author{
Terence Chiu and Ian A. Reid
}

\begin{abstract}
Nitric oxide plays an important role in the regulation of arterial pressure by its actions to dilate vascular smooth muscle, alter sympathetic neural activity, and modulate the vasoconstrictor action of norepinephrine, angiotensin II and vasopressin. Nitric oxide may also influence blood pressure regulation by altering the secretion of renin and vasopressin. To test this possibility, we investigated the effects of inhibiting nitric oxide synthesis on the cardiovascular, renin and vasopressin responses to hypotensive hemorrhage, a situation in which the renin-angiotensin system and vasopressin contribute significantly to the control of blood pressure. Arterial blood was withdrawn from conscious, chronically-prepared rabbits at $1.0 \mathrm{ml} / \mathrm{kg} / \mathrm{min}$ for $15 \mathrm{~min}$ under control conditions, and during i.v. infusion of the nitric oxide synthase inhibitor L-NAME. Hemorrhage decreased mean arterial pressure from $69 \pm 2$ to $45 \pm 4 \mathrm{~mm}$ $\mathrm{Hg}(p<0.01)$ and increased heart rate from $211 \pm 10$ to $270 \pm 15 \mathrm{bpm}(p<0.05)$. Plasma renin activity increased from $7.7 \pm 1$ to $36.1 \pm 9.6 \mathrm{ng} / \mathrm{ml} / 2 \mathrm{~h}$ at $15 \mathrm{~min}(p<0.01)$, while plasma vasopressin concentration increased from $1.7 \pm 0.6$ to $183.2 \pm 98.5 \mathrm{pg} / \mathrm{ml}(p<0.05)$. Infusion of L-NAME increased blood pressure and plasma vasopressin concentration, and decreased heart rate and plasma renin activity. L-NAME markedly attenuated the hypotensive response to hemorrhage $(72 \pm 3$ to $62 \pm 4 \mathrm{mmHg})$, but did not alter the increases in heart rate, plasma renin activity or plasma vasopressin concentration. In separate experiments, L-NAME did not alter the setpoint or gain of the baroreceptor reflex control of heart rate. These results demonstrate that inhibition of nitric oxide synthesis significantly improves blood pressure regulation during hemorrhage, but indicate that this improvement is not associated with alterations in the heart rate, renin or vasopressin responses to hemorrhage. (Hypertens Res 1995; 18: 55-61)
\end{abstract}

Key Words: nitric oxide, hemorrhage, heart rate, blood pressure, renin, vasopressin

Nitric oxide synthesized in vascular endothelial cells plays an important role in the control of blood pressure by its direct action to dilate vascular smooth muscle $(1-4)$. There is also evidence that nitric oxide influences blood pressure regulation by indirect mechanisms including alterations in sympathetic activity and norepinephrine release, and modulation of the vasoconstrictor action of norepinephrine, angiotensin II, vasopressin and endothelin (5-12).

Recently, nitric oxide has been implicated in the regulation of the secretion of renin (13-21) and vasopressin (22-27), raising the possibility that it may influence blood pressure indirectly by altering the secretion of these important pressor hormones. The aim of the present investigation was to test this possibility by examining the effect of inhibiting nitric oxide synthesis on the cardiovascular, renin and vasopressin responses to hypotensive hemorrhage. Hemorrhage was chosen because it is a situation in which both the renin-angiotensin system and vasopressin contribute significantly to the defense of blood pressure $(28,29)$, and because recent evidence indicates that nitric oxide is involved in blood pressure regulation during hemorrhage $(30,31)$ and hemorrhagic shock $(32,33)$. Because the present results indicated that inhibition of nitric oxide synthesis exerts differential actions on the blood pressure and heart rate responses to hemorrhage, the effect of the inhibition on the baroreceptor reflex control of heart rate was also investigated. The experiments were performed in conscious animals to avoid the confounding effects of anesthesia and surgery on renin (34) and vasopressin (35) secretion, and interference with responses involving nitric oxide (36, 37).

\section{Methods}

The experiments were performed on male New

From the Department of Physiology, University of California, San Francisco, San Francisco, U.S.A.

This research was supported by NIH Grant HL-29714 and NASA Grant NAG 2-779.

Address for Reprints: Ian A. Reid, Ph.D., Department of Physiology, University of California, San Francisco, San Francisco, CA 94143-0444, U.S.A.

Received May 19, 1994; accepted in revised form July 28, 1994. 
Zealand White rabbits (Nitabell Rabbitry, Hayward, CA) weighing $2.5-3.5 \mathrm{~kg}$. The rabbits were housed in separate cages in a $12 \mathrm{~h}$ light-cycled and temperature controlled room. They were fed a commercial diet (Purina rabbit chow, Ralston-Purina, St. Louis, MO) and were provided water ad libitum. All surgical and experimental procedures were approved by the University of California, San Francisco Committee on Animal Research.

\section{Surgical Preparation}

Surgery for chronic implantation of arterial and venous catheters was performed under aseptic conditions. The rabbits were anesthetized with ketamine (Parke-Davis, Morris Plains, NJ; 35-50 $\mathrm{mg} / \mathrm{kg}$ i.m.) and xylazine (Lloyd Laboratories, Shenandoah, IA; 5-10 mg/kg i.m.). Additional anesthetic was administered as required. A catheter consisting of $10 \mathrm{~cm}$ medical grade Silastic (Dow-Corning Corp., Midland, MI) connected to PE60 tubing was inserted into a femoral artery and advanced into the aorta to a point distal to the kidneys. Two Tygon catheters were inserted into a jugular vein and positioned near the heart. The three catheters were led s.c. to a point between the scapulae where they emerged through a small skin incision and were protected in a pocket of a nylon mesh jacket (Alice King Chatham, Los Angeles, CA). The rabbits were allowed to recover for at least three days following surgery, during which time they were treated with ampicillin (Sigma Chemical Co., St. Louis, MO; $10 \mathrm{mg} /$ day i.v.). Lactated Ringer's solution was administered s.c. if necessary to prevent dehydration. Catheters were flushed with sterile heparinized $0.9 \%$ saline $(1,000 \mathrm{U} / \mathrm{ml})$ at least every other day. During the recovery period, the rabbits were brought to the laboratory and accustomed to the experimental environment.

\section{Experimental Protocols}

On the day of an experiment, a rabbit was brought to the laboratory where it rested comfortably in a partly covered cage. Arterial blood pressure and heart rate were monitored continuously using a pressure transducer (Cobe Laboratories, Inc., Lakewood, $\mathrm{CO}$ ) and a custom-built cardiovascular analyzer. The cardiovascular data were simultaneously recorded on a Grass polygraph, and digitized continuously at $100 \mathrm{~Hz}$, stored, and analyzed using a PDP 11/23 + computer (Digital Equipment Corporation, Maynard, MA). Blood samples (volume $=2.5 \mathrm{ml}$ ) for analysis were collected from the femoral arterial cannula and replaced with an equal volume of sterile $0.9 \% \mathrm{NaCl}$. After blood pressure and heart rate had stabilized at their basal values for at least $15 \mathrm{~min}$, the cardiovascular and endocrine responses to hemorrhage were investigated under control conditions and following inhibition of nitric oxide synthesis. Each series of experiments was performed in the same rabbits on different days with one to seven days between experiments. The experiments were performed according to the following protocols.
Effect of Inhibition of Nitric Oxide Synthesis on the Cardiovascular and Endocrine Responses to Hemorrhage

Blood pressure and heart rate were monitored during a $15 \mathrm{~min}$ control period at the end of which a blood sample was collected. An infusion of $0.9 \%$ saline at $0.02 \mathrm{ml} / \mathrm{min}$ was then started and continued for the duration of the experiment. Fifteen minute after the start of the saline infusion, another blood sample was collected. The rabbits were then subjected to arterial hemorrhage. Blood was withdrawn from the femoral artery cannula with a Harvard infusion/withdrawal pump at approximately 1 $\mathrm{ml} / \mathrm{kg} / \mathrm{min}$ until a total of $15 \mathrm{ml} / \mathrm{kg}$ had been withdrawn. Because the arterial cannula was used for blood withdrawal, measurement of blood pressure and heart rate was discontinued during the actual hemorrhage, but was restarted as soon as the hemorrhage ended. Blood samples were collected at the midpoint and end of the hemorrhage; the blood withdrawn for hemorrhage was then reinfused over a period of five to ten min. After a $30 \mathrm{~min}$ recovery period, a final blood sample was collected.

The same procedure was repeated on a subsequent day, but the saline infusion was replaced with an infusion of the nitric oxide synthase inhibitor $N^{\mathrm{G}}$-nitro-L-arginine methyl ester hydrochloride (LNAME, Sigma Chemical Co., St. Louis, MO) (1, 38 ) at $0.5 \mathrm{mg} / \mathrm{kg} / \mathrm{min}$.

Effect of Inhibition of Nitric Oxide Synthesis on the Baroreceptor Reflex Control of Heart Rate

Baroreceptor reflex curves (heart rate vs. mean arterial pressure) were generated by measuring the heart rate responses to increases or decreases in arterial blood pressure produced with i.v. infusions of phenylephrine (Elkins-Sinn, Inc., Cherry Hill, NJ) and nitroprusside (Elkins-Sinn, Inc.). The doses of each drug were 2.6, 6.3, 12.5, and 25.0 $\mu \mathrm{g} / \mathrm{kg} / \mathrm{min}$ contained in a volume of $0.02-0.21 \mathrm{ml}$ $0.9 \% \mathrm{NaCl} / \mathrm{min}$. Each infusion lasted for $3-5 \mathrm{~min}$, and approximately 10 min elapsed between each infusion. Blood pressure and heart rate data collected during the last 1-2 min of each infusion were averaged and used to generate baroreceptor reflex curves. Baroreceptor reflex curves were generated in this manner during infusion of $0.9 \%$ saline $(0.02$ $\mathrm{ml} / \mathrm{min})$ and L-NAME $(0.5 \mathrm{mg} / \mathrm{kg} / \mathrm{min})$.

Steady state values of heart rate $(H R)$ and mean arterial pressure $(M A P)$ were analyzed as described previously (39) using the four-parameter sigmoidal logistic function:

$$
H R=\frac{A-D}{1+\left(\frac{M A P}{C}\right)^{B}}+D
$$

where $A$ and $D$ are the upper and lower plateaus of the baroreceptor reflex curve, $C$ is the mean arterial pressure at the midpoint of the heart rate range $\left(\mathrm{BP}_{50}\right.$, setpoint), and $B$ is the slope coefficient (40). Curves were fitted to the data by computer using a non-linear curve fitting program (NFIT, Island Products, Galveston, TX) based on the MarquardtLevenberg algorithm $(40,41)$.

The gain of the baroreceptor reflex at the $\mathrm{BP}_{50}$ 
(i.e. when $M A P=C$ ) was calculated as:

$$
\operatorname{GAIN}_{50}=-\frac{B(A-D)}{4 C}
$$

Baroreceptor reflex curves for each individual experiment were analyzed in this fashion and the resulting parameters were used for statistical analysis. In addition, $H R$ and $M A P$ data generated in the presence of saline or L-NAME were averaged, and the means fitted to construct a baroreceptor reflex curve for each treatment.

\section{Analytical Methods}

Plasma Renin Activity

Plasma renin activity (PRA) was measured using a radioimmunoassay for angiotensin I and expressed as nanograms angiotensin I generated per ml plasma during a two hour incubation at $37^{\circ} \mathrm{C}$ and $\mathrm{pH}$ $6.5(\mathrm{ng} / \mathrm{ml} / 2 \mathrm{~h})(42)$.

Plasma Vasopressin Concentration

Plasma AVP concentration was determined by radioimmunoassay following extraction of plasma with bentonite (43).

Statistics

Results are expressed as the mean \pm SE. Data were analyzed using analysis of variance for repeated measures. When significant differences were detected by analysis of variance, multiple comparisons were made using the Neuman-Keuls or Dunnett test (44). Single comparisons were made using the paired $t$ -
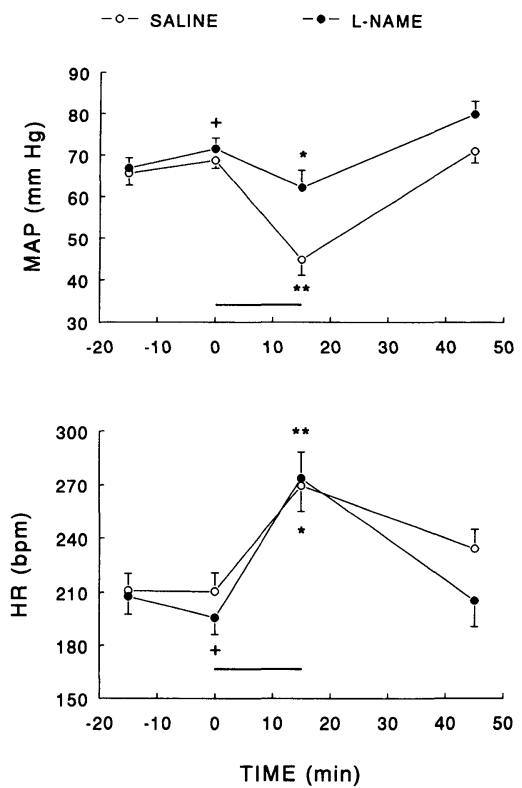

Fig. 1. Effects of hemorrhage on mean arterial pressure and heart rate during infusion of $L-N A M E$ or the saline vehicle. Infusion of $L-N A M E$ or saline was started immediately after completion of control measurements at -15 min and continued for the duration of the experiment. Blood was withdrawn from 0 to 15 min as indicated by the horizontal bar. Values represent the mean $\pm S E$ of observations made in six rabbits. ${ }^{+} \mathrm{p}<0.05$ compared to -15 min value. ${ }^{*} \mathrm{p}<0.05,{ }^{* *} \mathrm{p}<0.01$ compared to 0 min value. test. Changes were considered to be statistically significant when $p<0.05$.

\section{Results}

The cardiovascular responses to hemorrhage are summarized in Fig. 1. Withdrawal of $15 \mathrm{ml} / \mathrm{kg}$ blood over $15 \mathrm{~min}$ decreased mean arterial pressure (MAP) from $69 \pm 2$ to $45 \pm 4 \mathrm{mmHg}(p<0.01)$ and increased heart rate (HR) from $211 \pm 10$ to 270 $\pm 15 \mathrm{bpm}(p<0.05)$. MAP and HR rapidly returned to near their control values following retransfusion of the blood. Infusion of L-NAME increased MAP by $5 \pm 1 \mathrm{mmHg}(p<0.05)$ and decreased HR by $12 \pm 3 \mathrm{bpm}(p<0.05)$. In the presence of L-NAME, hemorrhage reduced MAP from $72 \pm 3$ to $62 \pm 4 \mathrm{mmHg}(p<0.05)$. Thus, L-NAME markedly reduced the hypotensive response to hemorrhage $(9 \pm 4$ vs. $24 \pm 5 \mathrm{mmHg}, p<0.05)$. On the other hand, L-NAME did not alter the HR response to hemorrhage $(196 \pm 10$ to $274 \pm 15$ bpm, $p<0.01)$.

The effect of L-NAME on the baroreceptor reflex control of heart rate is shown in Fig. 2 and Table 1. Infusion of L-NAME did not alter the $\mathrm{BP}_{50}$ or Gain $_{50}$ of the baroreceptor reflex curve indicating that there were no changes in baroreceptor reflex setpoint or sensitivity. L-NAME also failed to alter the upper plateau of the curve, but did reduce the lower plateau of the curve by $31 \mathrm{bpm}(p<0.02)$.

The effects of hemorrhage and L-NAME on plasma renin activity are summarized in Fig. 3. Hemorrhage increased plasma renin activity from $7.7 \pm 1.1$ to $17.4 \pm 3.1 \mathrm{ng} / \mathrm{ml} / 2 \mathrm{~h}$ at $7.5 \mathrm{~min}$ and to $36.1 \pm 9.6 \mathrm{ng} / \mathrm{ml} / 2 \mathrm{~h}$ at $15 \mathrm{~min}(p<0.01)$. Infusion of L-NAME decreased plasma renin activity from $10.1 \pm 2.6$ to $6.4 \pm 2.7 \mathrm{ng} / \mathrm{ml} / 2 \mathrm{~h}(p<0.05)$, but did not alter the subsequent plasma renin activity response to hemorrhage (to $15.2 \pm 5.7 \mathrm{ng} / \mathrm{ml} / 2 \mathrm{~h}$ at 7.5 min and to $38.3 \pm 8.9 \mathrm{ng} / \mathrm{ml} / 2 \mathrm{~h}$ at $15 \mathrm{~min}, p<$ $0.001)$.

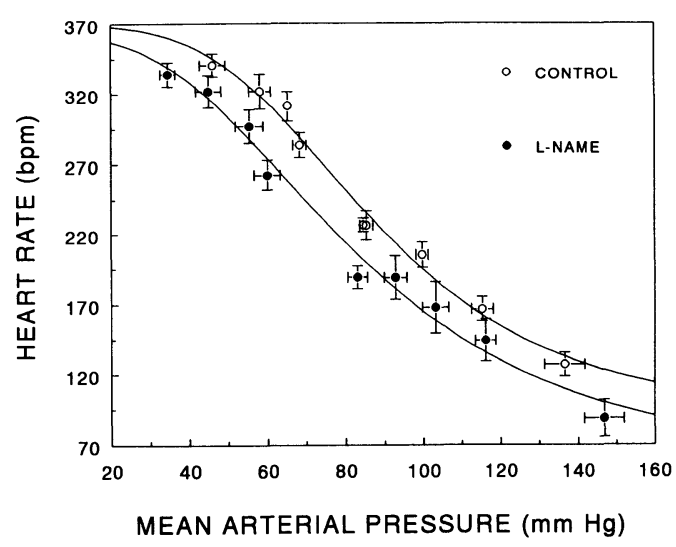

Fig. 2. Relationship between heart rate and mean arterial pressure under control conditions and during infusion of $L-N A M E$. Values represent the mean $\pm S E$ of observations made in nine rabbits. The parameters of the two curves are shown in Table 1. 
Table 1. Analysis of Cardiac Baroreceptor Reflex Curves Obtained during Infusion of Saline and L-NAME

\begin{tabular}{lcc}
\hline & Saline & L-NAME \\
\hline Upper plateau (bpm) & $352 \pm 8$ & $346 \pm 9$ \\
Lower plateau (bpm) & $124 \pm 7$ & $93 \pm 11^{*}$ \\
$\mathrm{BP}_{50}(\mathrm{mmHg})$ & $85 \pm 3$ & $81 \pm 4$ \\
Gain $_{50}(\mathrm{bpm} / \mathrm{mmHg})$ & $-3.9 \pm 0.3$ & $-3.7 \pm 0.4$ \\
\hline
\end{tabular}

Values represent the mean $\pm \mathrm{SE}$ of observations made in nine rabbits.

${ }^{*} p<0.05$ compared to corresponding saline value.

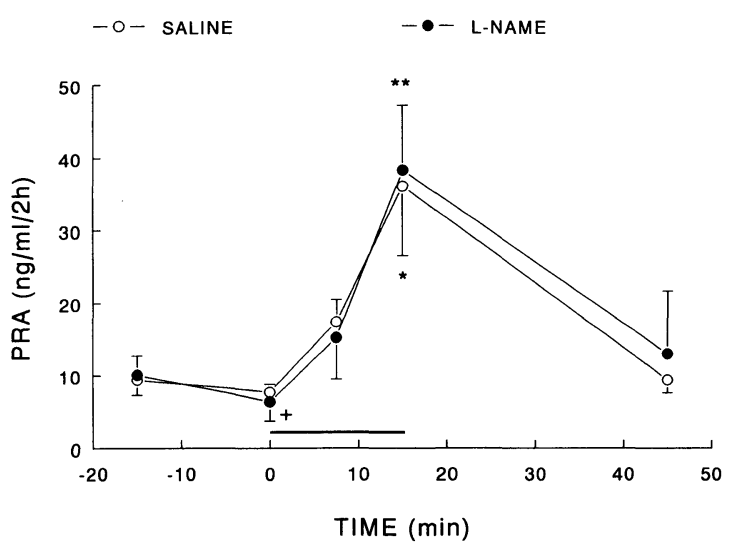

Fig. 3. Effect of hemorrhage on plasma renin activity during infusion of $L-N A M E$ or saline vehicle. Infusion of L-NAME or saline was started immediately after completion of control measurements at $-15 \mathrm{~min}$ and continued for the duration of the experiment. Values represent the mean $\pm S E$ of observations made in six rabbits. ${ }^{+} \mathrm{p}<0.05$ compared to -15 min value. ${ }^{*} \mathrm{p}<0.01,{ }^{* *} \mathrm{p}<0.001$ compared to 0 min value.

The effects of hemorrhage and L-NAME on plasma vasopressin concentration are shown in Fig. 4. Hemorrhage increased plasma vasopressin concentration from $1.7 \pm 0.6$ to $12.5 \pm 8.3 \mathrm{pg} / \mathrm{ml}$ at $7.5 \mathrm{~min}$ and to $183.2 \pm 98.5 \mathrm{pg} / \mathrm{ml}$ at $15 \mathrm{~min}(p<0.01)$. Infusion of L-NAME increased plasma vasopressin concentration from $1.7 \pm 0.4$ to $2.7 \pm 0.6 \mathrm{pg} / \mathrm{ml}$ ( $p$ $<0.05$ ), but did not reduce the subsequent plasma vasopressin response to hemorrhage (to $3.5 \pm 0.7$ $\mathrm{pg} / \mathrm{ml}$ at $7.5 \mathrm{~min}$ and to $125.1 \pm 50.0 \mathrm{pg} / \mathrm{ml}$ at 15 $\min , p<0.001)$.

\section{Discussion}

In the present study, removal of $15 \mathrm{ml} / \mathrm{kg}$ blood decreased arterial pressure by $24 \mathrm{mmHg}$. This was associated with a marked tachycardia and by increases in plasma renin activity and plasma vasopressin concentration, which are all well characterized responses to hypovolemia and hypotension $(28,29,45)$. L-NAME was used to investigate the role of nitric oxide in the cardiovascular and endocrine response to hemorrhage. L-NAME is one of a group of closely related derivatives of L-arginine which are competitive inhibitors of the enzyme nitric oxide synthase $(1,38)$. As has been observed in

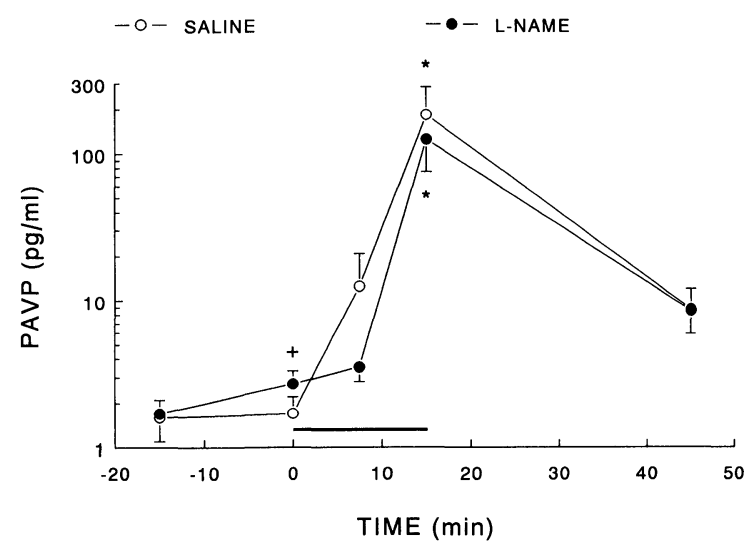

Fig. 4. Effect of hemorrhage on plasma vasopressin concentration during infusion of L-NAME or saline vehicle. Infusion of $L-N A M E$ or saline was started immediately after completion of control measurements at $-15 \mathrm{~min}$ and continued for the duration of the experiment. Values represent the mean $\pm S E$ of observations made in six rabbits. ${ }^{+} \mathrm{p}<0.05$ compared to -15 min value. ${ }^{*} \mathrm{p}<0.01,{ }^{* *} \mathrm{p}$ $<0.001$ compared to 0 min value.

the rabbit and other species $(2,5,20,30,38,46)$, administration of L-NAME increased arterial pressure, presumably as a result of removal of the vasodilator action of nitric oxide released from the vascular endothelium (2) or from nitroxidergic vasodilator nerves $(47,48)$, and decreased heart rate, presumably as a reflex response to the increase in blood pressure.

A major finding in the present investigation was that L-NAME markedly attenuated the hemorrhageinduced reduction in blood pressure. Thus, the decrease in mean arterial pressure in the presence of L-NAME was less than $40 \%$ of that in its absence. This finding is consistent with results obtained by other investigators. Zingarelli et al. (32) reported that administration of L-NAME to anesthetized rats subjected to hemorrhagic shock increased arterial pressure and prolonged survival time. Klabunde et al. (30) observed that administration of another nitric oxide synthase inhibitor, $N^{\mathrm{G}}$-methyl-L-arginine, produced rapid and complete recovery of arterial pressure in anesthetized hemorrhaged rats, primarily by increasing total peripheral resistance. However, it should be pointed out that the inhibitor produced a similar increase in blood pressure in normal rats. In both studies, the effects of nitric oxide 
synthase inhibition were reversed by administration of L-arginine. Recently, Koch et al. (31) reported that administration of L-NAME to conscious rabbits increased the blood loss required to decrease arterial pressure to below $40 \mathrm{mmHg}$. These studies and the present results all indicate that nitric oxide contributes significantly to the hypotension induced by hemorrhage. This apparently detrimental action of nitric oxide may help to maintain tissue perfusion in hypovolemic and hypotensive states. The origin of this nitric oxide, and the mechanism by which hemorrhage increases its synthesis remain to be determined.

Nitric oxide could contribute to the hypotensive response to hemorrhage in several different ways. These include a direct action to dilate vascular smooth muscle, alterations in sympathetic activity and norepinephrine release, and modulation of the action of several important vasoconstrictors including norepinephrine, angiotensin II, vasopressin and endothelin (5-12). Nitric oxide may also influence blood pressure regulation during hemorrhage by altering the secretion of renin and vasopressin. This proposal is based on the fact that both the reninangiotensin system and vasopressin contribute substantially to blood pressure regulation during hemorrhage $(28,29)$, and that nitric oxide has been implicated in the control of the secretion of renin (13-21) and vasopressin (22-27). The proposal was tested in the present study by investigating the effects of inhibition of nitric oxide synthesis on the renin and vasopressin responses to hemorrhage.

As has been reported previously $(15,16,21,25)$, inhibition of nitric oxide synthesis decreased resting plasma renin activity. There is some disagreement in the literature concerning the mechanism of this decrease. It has been proposed that the decrease results from a combination of increased renal perfusion pressure and withdrawal of sympathetic neural tone to the kidneys (16). Others, however, have provided evidence that the suppression of renin secretion by nitric oxide synthesis inhibition can occur independently of the hemodynamic and neural mechanisms that inhibit renin secretion (13-15). Thus it is possible that the suppression of plasma renin activity in the present study resulted from removal of a tonic stimulatory action of endogenous nitric oxide on renin secretion.

Although L-NAME suppressed basal renin secretion, it did not alter the renin response to hemorrhage, suggesting that nitric oxide is not involved in the renal baroreceptor control of renin secretion. This conclusion differs from that of other investigators who observed that inhibition of nitric oxide synthesis suppresses pressure-dependent renin release $(18-20)$. However, it is possible that the combination of hypovolemia and hypotension in the present study was sufficient to produce maximal stimulation of renin secretion. In any case, the present results indicate that the action of L-NAME to attenuate the hypotensive response to hemorrhage does not result from enhanced secretion of renin.

Recent evidence indicates that nitric oxide also plays a role in the control of vasopressin secretion.
The enzyme nitric oxide synthase is present in magnocellular neurons of the supraoptic and paraventricular nuclei of the hypothalamus, and in the posterior pituitary gland (22-24), and enzyme activity in these regions changes in response to alterations in sodium or water balance $(22,23)$. Nitric oxide donors have been reported to alter the release of vasopressin when administered to conscious rats (27) or added to rat hypothalamic explants (26). Recently, we reported that blockade of nitric oxide synthesis in conscious rabbits increased resting plasma vasopressin concentration, suggesting an inhibitory role for nitric oxide in the control of vasopressin secretion (25). L-NAME also increased resting plasma vasopressin concentration in the present study, but did not alter the subsequent vasopressin response to hemorrhage. This latter finding is consistent with our previous observation that L-NAME did not alter the vasopressin response to hypotension induced by nitroprusside infusion (25). Inhibition of nitric oxide synthesis also failed to alter the vasopressin responses to osmotic stimulation in rabbits (25) and water deprivation in rats (49). Thus, the attenuation of the hypotensive response to hemorrhage by L-NAME cannot be attributed to enhanced secretion of vasopressin.

It is worth emphasizing that L-NAME did not alter the renin or vasopressin responses to hemorrhage despite the fact that it reduced the hypotension. Thus, for a given decrease in arterial pressure, the renin and vasopressin responses to hemorrhage would have been larger, suggesting that nitric oxide may in fact inhibit the secretion of these hormones during hemorrhage. However, the renin and vasopressin responses to hypovolemia result from reductions in atrial as well as arterial pressure $(28,34)$, but only arterial pressure was measured in this study. Thus, the question of the role of nitric oxide in the control of renin and vasopressin secretion during hemorrhage requires further investigation.

Despite its action to decrease the hypotensive action of hemorrhage, L-NAME did not alter the heart rate response. This dissociation of the heart rate and blood pressure responses suggested that LNAME might alter the baroreceptor reflex control of heart rate. However, analysis of the cardiac baroreflex in the present study showed that LNAME did not alter the setpoint or gain of the baroreceptor reflex, although as reported by $\mathrm{Du}$ et al. (46), it did reduce the lower plateau of the baroreceptor reflex curve. This lack of effect of inhibition of nitric oxide synthesis on the cardiac baroreflex is consistent with the results of other investigators $(5,11,46)$.

In summary, the present results demonstrate that inhibition of nitric oxide synthesis with L-NAME in conscious rabbits markedly attenuates the hypotensive response to hemorrhage. This attenuation does not appear to result from enhanced secretion of renin or vasopressin, or from an alteration in the baroreceptor reflex control of heart rate. Thus, the attenuation can best be attributed to removal of the action of nitric oxide to dilate vascular smooth mus- 
cle, alter sympathetic neural activity, or modulate the vasoconstrictor action of norepinephrine, angiotensin II, vasopressin and endothelin.

\section{Acknowledgments}

The expert assistance of Lance Chou, Dina San Juan, and Juli Evans is gratefully acknowledged.

\section{References}

1. Moncada S, Palmer RMJ, Higgs EA: Nitric oxide: physiology, pathophysiology, and pharmacology. Pharmacol Rev 1991; 43: 109-142.

2. Rees DD, Palmer RMJ, Moncada S: Role of endothelium-derived nitric oxide in the regulation of blood pressure. Proc Natl Acad Sci USA 1989; 86: 3375-3378.

3. Gardiner SM, Compton AM, Bennett T, Palmer RMJ, Moncada S: Control of regional blood flow by endothelium-derived nitric oxide. Hypertension 1990; 15: 486-492.

4. Moncada S: The L-arginine: nitric oxide pathway. Acta Physiol Scand 1992; 145: 201-227.

5. Gardiner SM, Compton AM, Kemp PA, Bennett T: Effects of $N^{\mathrm{G}}$-nitro-L-arginine methyl ester or indomethacin on differential regional and cardiac haemodynamic actions of arginine vasopressin and lysine vasopressin in conscious rats. Br J Pharmacol 1991; 102: 65-72.

6. Molnar M, Hertelendy F: N $\omega$-Nitro-L-arginine, an inhibitor of nitric oxide synthesis, increases blood pressure in rats and reverses the pregnancy-induced refractoriness to vasopressor agents. Am J Obstet Gynecol 1992; 166: 1560-1567.

7. Lerman A, Sandok EK, Hildebrand FL Burnett JC: Inhibition of endothelium-derived relaxing factor enhances endothelin-mediated vasoconstriction. Circulation $1992 ; 85$ : 1894-1898.

8. Gonzalez C, Fernandez A, Martin C, Moncada S, Estrada C: Nitric oxide from endothelium and smooth muscle modulates responses to sympathetic nerve stimulation: implications for endotoxin shock. Biochem Biophys Res Commun 1992; 186: 150-156.

9. Szabo C, Csaki C, Benyo Z, Reivich M, Kovach AGB: Role of the L-arginine-nitric oxide pathway in the changes in cerebrovascular reactivity following hemorrhagic hypotension and retransfusion. Circ Shock 1992; 37: 307-316.

10. Togashi H, Sakuma I, Yoshioka M, et al: A central nervous system action of nitric oxide in blood pressure regulation. J Pharmacol Exp Ther 1992; 262: 343-347.

11. Halbrugge T, Lutsch K, Thyen A, Graefe K-H: Role of nitric oxide formation in the regulation of haemodynamics and the release of noradrenaline and adrenaline. Arch Pharmacol 1991; 344: 720-727.

12. Ito S, Arima S, Ren YL, Juncos LA, Carretero OA: Endothelium derived relaxing factor/nitric oxide modulates angiotensin II action in the isolated microperfused rabbit afferent but not efferent arteriole. J Clin Invest 1993; 91: 2012-2019.

13. Gardes J, Poux J-M, Gonzalez M-F, Alhenc-Gelas F, Menard J: Decreased renin release and constant kallikrein secretion after injection of L-NAME in isolated perfused rat kidney. Life Sci 1992; 50: 987-993.

14. Kurtz A, Kaissling B, Busse R, Baier W: Endothelial cells modulate renin secretion from isolated mouse juxtaglomerular cells. J Clin Invest 1991; 88: 1147-
1154.

15. Johnson RA, Freeman RH: Pressure natriuresis in rats during blockade of the L-arginine/nitric oxide pathway. Hypertension 1992; 19: 333-338.

16. Sigmon DH, Carretero OA, Beierwaltes WH: Endothelium-derived relaxing factor regulates renin release in vivo. Am J Physiol 1992; 263: F256-F261.

17. Mundel P, Bachmann S, Bader M, et al: Expression of nitric oxide synthase in kidney macula densa cells. Kidney Int 1992; 42: 1017-1019.

18. Scholz H, Kurtz A: Involvement of endothelium-derived relaxing factor in the pressure control of renin secretion from isolated perfused kidney. J Clin Invest 1993; 91: 1088-1094.

19. Naess PA, Christensen G, Kirkeboen KA, Kiil F: Effect on renin release of inhibiting renal nitric oxide synthesis in anaesthetized dogs. Acta Physiol Scand 1993; 148: 137-142.

20. Persson PB, Baumann JE, Ehmke H, Hackenthal E, Kirchheim HR, Nafz B: Endothelium-derived NO stimulates pressure-dependent renin release in conscious dogs. Am J Physiol 1993; 264: F943-F947.

21. Reid IA, Bui H, Chou L: Role of nitric oxide in the renin and heart rate responses to beta adrenergic stimulation. Hypertension 1994; 23 (suppl. I): I-49I-53.

22. Sagar SM, Ferriero DM: NADPH diaphorase activity in the posterior pituitary: relation to neuronal function. Brain Res 1987; 400: 348-352.

23. Pow DV: NADPH-diaphorase (nitric oxide synthase) staining in the rat supraoptic nucleus is activity-dependent: possible functional implications. J Neuroendocrinol 1992; 4: 377-380.

24. Calka J, Block CH: Relationship of vasopressin with NADPH-diaphorase in the hypothalamo-neurohypophyseal system. Brain Res Bull 1993; 32: 207-210.

25. Goyer M, Bui H, Chou L, Evans J, Keil LC, Reid IA: Effect of inhibition of nitric oxide synthesis on vasopressin secretion in conscious rabbits. Am J Physiol 1994; 266: H822-H828.

26. Yasin S, Costa A, Trainer P, Windle R, Forsling ML, Grossman A: Nitric oxide modulates the release of vasopressin from rat hypothalamic explants. Endocrinology 1993; 133: 1466-1469.

27. Ota M, Crofton JT, Festavan GT, Share L: Evidence that nitric oxide can act centrally to stimulate vasopressin release. Neuroendocrinology 1993; 57: 955959.

28. Schadt JC, Ludbrook J: Hemodynamic and neurohumoral responses to acute hypovolemia in conscious mammals. Am J Physiol 1991; 260: H305-H318.

29. Reid IA, Schwartz J: Role of vasopressin in the control of blood pressure, in Martini L, Ganong WF (eds): Frontiers in Neuroendocrinology. New York, Raven Press, 1984, pp 177-197.

30. Klabunde RE, Slayton KJ, Ritger RC: $N^{\mathrm{G}}$-Methyl-Larginine restores arterial pressure in hemorrhaged rats. Circ Shock 1993; 40: 47-52.

31. Koch MA, Neidt MR, Hasser EM, Schadt JC: Influence of nitric oxide (NO) on the hemodynamic response to hemorrhage in the conscious rabbit. FASEB J 1993; 7: A431.

32. Zingarelli B, Squadrito $\mathrm{F}$, Altavilla $\mathrm{D}$, et al: Evidence for a role of nitric oxide in hypovolemic hemorrhagic shock. J Cardiovasc Pharmacol 1992; 19: $982-986$.

33. Thiemermann C, Szabo C, Mitchell JA, Vane JR: Vascular hyporeactivity to vasoconstrictor agents and hemodynamic decompensation in hemorrhagic shock is mediated by nitric oxide. Proc Natl Acad Sci USA 1993; 90: 267-271. 
34. Keeton TK, Campbell WB: The pharmacologic alteration of renin release. Pharmacol Rev 1980; 32: 81-227.

35. Bonjour JP, Malvin RL: Plasma concentrations of $\mathrm{ADH}$ in conscious and anesthetized dogs. Am J Physiol 1970; 218: 1128-1132.

36. Gerkens JF: Barbiturate inhibition of endotheliumdependent dilatation of blood- and Krebs-perfused rat tail arteries. Eur J Pharmacol 1987; 134: 293-301.

37. Muldoon SM, Hart JL, Bowen KA, Freas W: Attenuation of endothelium-mediated vasodilation by halothane. Anesthesiology 1988; 68: 31-37.

38. Rees DD, Palmer RMJ, Schulz R, Hodson HF, Moncada S: Characterization of three inhibitors of endothelial nitric oxide synthase in vitro and in vivo. Br J Pharmacol 1990; 101: 746-752.

39. Wong J, Chou L, Reid IA: Role of $A_{1}$ receptors in the resetting of the baroreflex control of heart rate by angiotensin II in the rabbit. J Clin Invest 1993; 91: 1516-1520.

40. Rodbard D: Lessons from the computerization of radioimmunoassays: an introduction to the basic principles of modelling, in Rodbard D, Forti G (eds): Computers in Endocrinology. New York, Raven Press, 1984, pp 75-99.

41. Bevington PR: Data Reduction and Error Analysis for the Physical Sciences. New York, McGraw-Hill, 1969.
42. Menard J, Catt KJ: Measurement of renin activity, concentration and substrate in rat plasma by radioimmunoassay of angiotensin I. Endocrinology 1972; 90: 422-430.

43. Keil LC, Severs WB: Reduction in plasma vasopressin levels of dehydrated rats following acute stress. Endocrinology 1977; 100: 30-38.

44. Winer BJ: Statistical Principles in Experimental Design. New York, McGraw-Hill, 1971.

45. Blair ML, Hisa $H$, Sladek CD, Radke KJ, Gengo FM: Dual adrenergic control of renin during nonhypotensive hemorrhage in conscious dogs. Am J Physiol 1991; 260: E910-E919.

46. Du Z-Y, Dusting GJ, Woodman OL: Baroreceptor reflexes and vascular reactivity during inhibition of nitric oxide synthesis in conscious rabbits. Eur $J$ Pharmacol 1992; 214: 21-26.

47. Toda N, Kitamura Y, Okamura T: Neural mechanism of hypertension by nitric oxide synthase inhibitor in dogs. Hypertension 1993; 21: 3-8.

48. Toda N, Okamura $\mathrm{T}$ : Regulation by nitroxidergic nerve of arterial tone. NIPS 1992; 7: 148-152.

49. Summy-Long JY, Bui V, Mantz S, Koehler E, Weisz J, Kadekaro M: Central inhibition of nitric oxide synthase preferentially augments release of oxytocin during dehydration. Neurosci Lett 1993; 152: 190193. 